\title{
CLÁSSICOS DO CINEMA NAS AULAS DE CIÊNCIAS - A FÍSICA EM 2001: UMA ODISSEIA NO ESPAÇO
}

\author{
Movies classics in science classes \\ - Physics in 2001: a space odyssey
}

Luís Paulo Piassi ${ }^{1}$

Resumo: Quando se fala em usar ficção científica em aulas de física, o filme 2001: uma odisseia no espaço, dirigido por Stanley Kubrick, aparece como referência mais ou menos obrigatória. Nosso objetivo é argumentar que o interesse da comunidade de educadores em física por esse filme é consequência de uma escolha narrativa de Kubrick e de Arthur Clarke, o prestigiado escritor de ficção científica que, junto com o diretor, elaborou o roteiro. Mostramos, empregando instrumentos teóricos derivados da semiótica greimasiana, que, nesse particular segmento da obra, a opção foi expressar uma determinada visão sobre o ser humano e sua relação com o mundo físico por meio da ciência. Concluímos que uma obra como a de Kubrick vai muito além de um recurso didático atraente, sendo uma referência cultural importante, uma narrativa sobre a ciência e os desejos humanos, expressos na ideologia de uma sociedade que se sustenta no conhecimento científico.

Palavras-chave: Cinema. Ficção científica. Ensino de física. Exploração espacial. Semiótica.

\begin{abstract}
In proposals for using science fiction in physics classes, the movie 2001: A Space Odyssey, directed by Stanley Kubrick, appears as more or less mandatory. In this paper we intend to argue that the interest of the community of physics educators about this film is the result of a narrative choice of Stanley Kubrick and Arthur C. Clarke, the renowned science fiction writer who, along with the director wrote the screenplay. We show, using theoretical tools derived from Greimasian semiotics, which in this particular segment of the movie picture, the choice was to express a particular view about humanity and its relationship with the physical world through science. We conclude that a work like Kubrick's film goes beyond the potential for a mere attractive teaching resource, being an important cultural reference on the role played by science in the socio-historical context.
\end{abstract}

Keywords: Movies. Science fiction. Physics teaching. Space exploration. Semiotics.

${ }^{1}$ Universidade de São Paulo (USP), Escola de Artes, Ciências e Humanidades. Rua Arlindo Bettio, 1.000, CEP 03828-000, São Paulo, SP, Brasil. E-mail: lppiassi@usp.br 


\section{Uma odisseia no espaço da sala de aula}

Quando se fala em usar ficção científica em aulas de física, o filme 2001: uma odisseia no espaço (2001), dirigido por Stanley Kubrick, aparece como uma referência mais ou menos obrigatória. De fato, as cenas encontradas nessa obra cinematográfica, aparentemente estudadas e elaboradas para retratar uma obediência às leis físicas, contrastam com as cenas de guerra espacial em Star wars (2006) e outros filmes congêneres, onde essa obediência parece ser deixada em segundo plano. Isso, possivelmente, chama a atenção de quem tem conhecimentos de física, e são vários os professores que tiveram a ideia de usar cenas desse filme específico em suas aulas.

Borgwald (1993) toma como base o movimento rotacional da estação espacial do filme, que produz, em seu interior, a sensação de gravidade por meio do efeito centrífugo. $O$ autor realiza cálculos baseado naquilo que pode ser observado nas cenas e propõe uma discussão didática envolvendo os conceitos de gravidade, inércia e forças inerciais. Neves (2000), por sua vez, emprega filmes de ficção espacial em uma atividade didática comparativa, mostrando que as ideias aristotélicas de movimento, muitas vezes associadas a concepções espontâneas dos estudantes, são também veiculadas em filmes como Star wars (2006), ao passo que uma obra como 2001: uma odisseia no espaço (2001) retrata os fenômenos de forma consistente com as leis newtonianas. Outros trabalhos, como o de Signorelli (2003), também propõem usar as cenas da segunda parte de filme para discussões sobre inércia e referenciais. Outros autores, como Dubeck $(1990,1993)$ e Fraknoi (2002), também mencionam as possíveis qualidades didáticas desse filme como recurso no ensino de conceitos físicos. No conveniente ano de 2001, uma questão de física de um importante vestibular fez menção explícita à obra:

Algo muito comum nos filmes de ficção científica é o fato de os personagens não flutuarem no interior das naves espaciais. Mesmo estando no espaço sideral, na ausência de campos gravitacionais externos, eles se movem como se existisse uma força que os prendesse ao chão das espaçonaves. Um filme que se preocupa com esta questão é "2001, uma Odisseia no Espaço", de Stanley Kubrick. Nesse filme a gravidade é simulada pela rotação da estação espacial, que cria um peso efetivo agindo sobre o astronauta. A estação espacial, em forma de cilindro oco, mostrada abaixo, gira com velocidade angular constante de 0,2 $\mathrm{rad} / \mathrm{s}$ em torno de um eixo horizontal $\mathrm{E}$ perpendicular à página. $\mathrm{O}$ raio $\mathrm{R}$ da espaçonave é $40 \mathrm{~m}$.

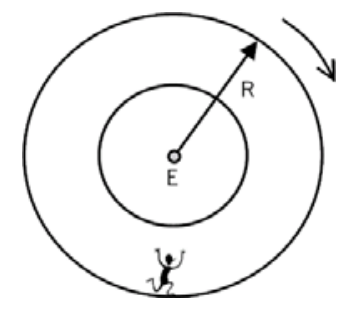

a) Calcule a velocidade tangencial do astronauta representado na figura. 
b) Determine a força de reação que o chão da espaçonave aplica no astronauta que tem massa $m=80 \mathrm{~kg}$. (UNIVERSIDADE ESTADUAL DE CAMPINAS, 2001, p. 106)

A própria existência da questão no exame e o discurso que embute uma crítica tácita a filmes em que "personagens que se movem como se existisse uma força que os prendesse ao chão da espaçonave" (UNIVERSIDADE ESTADUAL DE CAMPINAS, 2001, p. 106) são indícios de uma valorização da obra em função de sua suposta correção conceitual. É interessante observar que o enunciado da questão, embora não diga isso explicitamente, dá margem à interpretação de que as cenas de 2001: uma odisseia retratam situações onde se verifica 'ausência de campos gravitacionais', o que é conceitualmente falso. Nos materiais didáticos do projeto São Paulo Faz Escola, incluímos uma atividade (SÃO PAULO, 2010, p. 7), derivada de nossa prática didática (PIASSI, 2007, p. 317), que empregava cenas da segunda parte do filme para a discussão de conceitos ligados à inércia, referenciais e gravitação, atividade depois adaptada e aproveitada por um livro didático de Ensino Médio (PIETROCOLA et al., 2011, p. 371). Não por acaso, tratam-se, aproximadamente, das mesmas cenas que os outros professores citados escolheram para suas discussões ou propostas de sala de aula.

Nosso objetivo, no presente artigo, é argumentar que o interesse da comunidade de educadores em física por 2001: uma odisseia no espaço é consequência de uma escolha narrativa de Stanley Kubrick e de Arthur Clarke, o prestigiado escritor de ficção científica que, junto com o diretor, elaborou o roteiro do filme (GEDULD, 2000). Tentaremos mostrar que, nesse particular segmento da obra, a opção narrativa foi expressar uma determinada visão sobre o ser humano e sua relação com o mundo físico por meio da ciência, e, para isso, nos valemos dos instrumentos teóricos da semiótica de Greimas (1973) (GREIMAS; COURTÉS, 2008). Interessa-nos defender que a importância educacional de obras clássicas do cinema, como 2001: uma odisseia no espaço, vai além do seu uso como um mero recurso didático para o ensino de conceitos. A obra artística em si, como discurso sobre a ciência, possui uma valor pedagógico por sua importância cultural e pela mensagem que veicula, em um âmbito geral.

\section{Por que ler (e assistir) os clássicos}

É comum ouvirmos (ou lermos) afirmações a respeito do filme 2001: uma odisseia no espaço nas quais ele é referido como um clássico do cinema. Ítalo Calvino (1993) argumenta em favor da leitura dos clássicos a partir de algumas teses, dando destaque para uma tentativa de delimitação do que pode ou não ser considerado um clássico. Desses elementos, consideramos três pontos que julgamos fundamentais. O primeiro deles é que o clássico é uma obra que produz reconhecida e relevante inovação em alguns aspectos de seu campo. O segundo é que o clássico perdura e continua a ser mencionado como referência muito tempo depois de sua produção. O terceiro é que o clássico influencia outros campos da cultura, além daquele no qual ele foi produzido. Claro que esses três aspectos podem ser deturpados por objetivos e investimentos comerciais, sobretudo no caso do cinema, onde grandes corporações estão por trás das obras. No caso do filme em questão, no entanto, não nos parece ser o caso.

Antonio Candido (1995) defende a literatura como um direito, argumentando sobre seu poder inovador e, mais do que isso, transgressor, em relação às normas sociais estabeleci- 
das. E esse direito, no entender de Candido (1995), se concretiza a partir do ambiente escolar, com o ensino da literatura e a defesa de que os alunos tenham contato com as chamadas grandes obras da literatura. Se podemos considerar que o cinema também possui um sentido inovador e transgressor, que é capaz de produzir efeitos mais efetivos do que um puro lazer, estimulando a reflexão e um esforço cognitivo que pode propiciar uma experiência profunda ao espectador, talvez seja o caso de defender, como Candido (1995), a presença das grandes obras do cinema em sala de aula.

Nesse sentido, o filme 2001: uma odisseia no espaço atende a alguns requisitos importantes. Em primeiro lugar, sua influência cultural o torna, de acordo com os critérios que apontamos, um clássico. Mais do que isso, é uma espécie de clássico setorial, também entre os educadores na área de ensino de física, já que é visto como uma obra que traz inovação em sua linguagem, ao retratar, de forma supostamente fiel, as questões físicas envolvendo situações concretas da exploração espacial, ao contrário da maioria dos outros filmes, mais fantasiosos. Além disso, foi e continua sendo citado como obra de referência importante, não somente dentro, mas, sobretudo, fora da esfera artística do cinema e, particularmente, nos meios educacionais. Entretanto, a despeito disso tudo, apesar de ser um clássico do cinema, ou, até mesmo, pelas razões que levam a ser assim considerado, 2001: uma odisseia no espaço, dificilmente agrada de imediato aos adolescentes. Sua linguagem de longas cenas sem diálogos e ritmo lento está bem distante do tipo de produção que faz mais sucesso, com muita ação, aventura, romance e efeitos especiais espetaculares. O filme de Kubrick não proporciona nada disso. Isso parece invalidar aquilo que, em geral, é dado como a principal motivação para o uso da ficção científica em sala de aula: o interesse dos alunos pelos filmes. Mais ainda: contraria a ideia bastante razoável de que as melhores obras do cinema são, também, as mais particularmente efetivas em seu potencial didático.

Este é, porém, um falso dilema. Não podemos esperar de adolescentes, necessariamente, um entusiasmo imediato com qualquer produção artística refinada. Há que se levar em conta dois argumentos. O primeiro deles, bem expresso pelo escritor Julio Cortázar (1993, p. 161), questiona aqueles que defendem a "literatura acessível", baseada em "temas populares", mas que não suspeitam "que muitas vezes o leitor, por mais simples que seja, distinguirá instintivamente entre um conto mais difícil e complexo, mas que o obrigará a sair por um momento do seu pequeno mundo circundante e lhe mostrará outra coisa". Tal argumento é trazido também por Candido (1995) ao defender a literatura como direito. O segundo argumento é dado pelo educador francês Georges Snyders e complementa o primeiro. Segundo Snyders (1988), o papel da escola é confrontar o estudante com uma cultura elaborada, que responde a questões que a chamada cultura primeira, que ele traz de suas vivências, lhe coloca. Para ele, "a cultura primeira visa valores reais, fundamentais: em parte, ela os atinge, em parte, não o consegue: a cultura elaborada é uma chance muito maior de viver esses mesmos valores com plenitude" (SNYDERS, 1996, p. 24).

Isso implica, porém, que não podemos pressupor que a obra, por sua qualidade, irá encontrar ressonância no repertório cultural dos estudantes, e que irá, de imediato, comunicarse com eles. Mas isso não significa, igualmente, que precisamos nos restringir a obras de grande apelo popular. O que temos aqui é a tensão entre cultura primeira e cultura elaborada, mencionada por Snyders (1988). Levar os alunos a perceberem o valor em 2001: uma odisseia no espaço é um trabalho que aponta nessa direção. O interesse não precisa se vincular ao apelo da 
obra por conta de suas cenas emocionantes, ação e tudo o mais, embora tais valores - alegrias simples, nas palavras de Snyders (1988) - não devam ser descartados. É necessário realizar um trabalho para que os alunos percebam em que aspectos essa obra é capaz de dar conta de questões que estimulem seu interesse. Um dos fundamentos do trabalho é justamente um conhecimento mais aprofundado dos conteúdos interpretativos que a obra possa fornecer.

\section{Aspectos da ciência e da tecnologia em 2001}

O trecho que iremos analisar integra a segunda parte do filme, na qual o cientista Dr. Heywood Floyd vai até a Lua coletar informações sobre a descoberta de um estranho artefato ali descoberto sob o solo. Diversos veículos e artefatos espaciais aparecem em cena. As espaçonaves do filme e seus movimentos parecem ter sido concebidos com o cuidado de retratar a obediência a leis da física, tanto em sua operação quanto em seu projeto, de acordo com suas finalidades específicas. Uma primeira nave (Figura 1A), que leva Floyd da Terra a uma estação orbital (Figura 1B), tem a configuração de uma aeronave que necessita de asas e aerodinâmica para mover-se na atmosfera. Uma segunda nave, usada para o transporte desde a estação até a Lua, é esférica, um formato eficiente para o ambiente vazio do espaço, em que a imponderabilidade é constante (Figura 1C). Um terceiro, veículo adequado para transporte no solo lunar, tem a configuração vertical-horizontal semelhante a furgão, em um ambiente em que o efeito do peso, embora atenuado pela baixa gravidade, ainda é inescapável (Figura 1D).

Figura 1. Veículos e estação espacial usados por Heywood Floyd

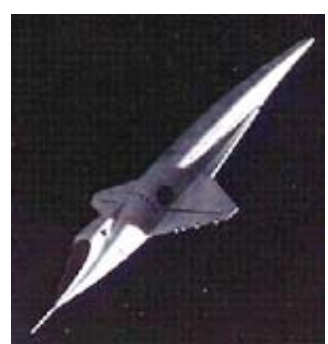

A

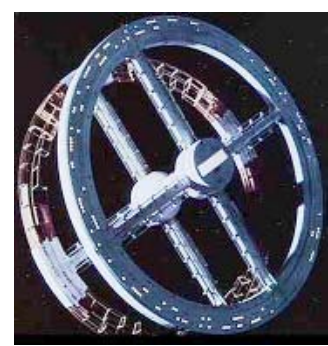

B

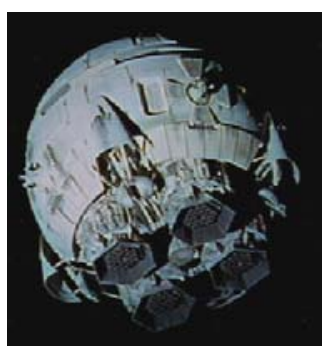

C

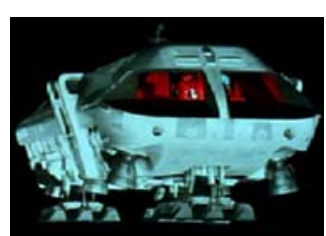

D

Fonte: 2001: uma odisseia no espaço (2001).

A primeira sequência que mostra o ônibus espacial da figura $1 \mathrm{~A}$ tem como destaque o fenômeno da flutuação de objetos. No interior do ônibus espacial, temos a situação de imponderabilidade, na medida em que a espaçonave esteja se movendo apenas sujeita à força gravitacional da Terra, sem o acionamento de motores. Nesse caso, a nave e todos os objetos dentro dela estão em uma situação equivalente à queda livre, e tudo se passa muito aproxima- 
damente como se não houvesse campos gravitacionais atuando. Uma caneta flutuante aparece em cena, aparentemente por ter escapado da mão de Floyd quando ele adormeceu. Uma comissária de bordo entra no compartimento com um caminhar vacilante, segurando-se nas laterais, pois não há força de atração impelindo-a para o pavimento da nave. Ela está sob imponderabilidade. Seus calçados, mostrados em close, exibem a expressão grip shoes, ou sapatos aderentes, necessários para ajudá-la a fixar-se no piso. Seu figurino conta com uma boina presa por um elástico, cobrindo totalmente os cabelos, o que evita que tanto a boina quanto os cabelos saiam flutuando nave afora. Ao mesmo tempo, dá-se destaque a determinados avanços tecnológicos, como o dos monitores de TV de espessura reduzida, colocada no encosto de cada uma das poltronas de passageiros.

A sequência seguinte, que mostra o ônibus espacial acoplando-se à estação orbital, prima pelos detalhes físicos, obedecendo fielmente às leis do movimento relativo, a partir dos três referenciais que mencionaremos adiante. As telas, controles e equipamentos, com o logotipo da indústria de computação IBM na cabine de comando, mostram a precisão das operações e confirmam as possibilidades de que tudo aquilo seja realmente factível, em um futuro próximo.

Dentro da estação espacial, tudo se passa como em um ambiente com gravidade. As pessoas andam normalmente e não há objetos flutuando. Isso ocorre por conta do efeito centrífugo: a estação tem o formato de uma grande roda e está em contínuo movimento de rotação. Em seu interior, o teto e o piso são claramente curvados, em um sentido côncavo. Floyd passa por um identificador de voz e, depois, para em uma cabine videofônica, para fazer uma ligação para casa. $\mathrm{O}$ videofone é composto de uma tela com uma câmera sobre ela, um tanto parecida com a configuração atual dos notebooks com webcam, mas em escala maior. $\mathrm{Na}$ janela da cabine, vemos o planeta Terra efetuando um movimento de revolução circular, com eixo excêntrico, situado fora de sua superfície. Exatamente o que veríamos da janela de uma estação espacial girante com aquelas dimensões. As cenas em que a Terra aparece não são tão convincentes quanto aquelas em que vemos a Lua. Isso é justificável, pois, na época de produção do filme, ainda não dispúnhamos de fotos coloridas da Terra vista do espaço. As primeiras foram obtidas no final de 1968.

$\mathrm{Na}$ sequência seguinte, ao som de Strauss, novas cenas interessantes. O lanche de bordo é composto por uma bandeja com compartimentos de alimentos líquidos, consumidos com canudos, adequado para ambientes com ausência de peso. A nave, esférica, convém em uma situação na qual não há sensação de peso, pois minimiza a área de contato com o espaço exterior, com diversas vantagens mecânicas, térmicas e econômicas. Isso produz a necessidade de adaptações na arquitetura dos ambientes, o que proporciona cenas como a clássica caminhada da comissária de bordo pelas paredes e a sequência que faz questão de mostrar, didaticamente, que, em uma nave desse tipo, a noção do que é em cima ou embaixo fica bastante difusa e relativa. Isso ocorre quando a comissária ingressa, supostamente de ponta-cabeça, na cabine de comando para servir aos pilotos. Um movimento giratório de câmera a coloca novamente de cabeça para cima. Ainda nessa nave, vemos a bandeja flutuar do colo de Floyd, salientando a ausência da sensação de peso e uma cena de humor sutil, com o personagem lendo as longas instruções de uso do sanitário em gravidade zero.

A nave pousa na base lunar, acionando seus retrofoguetes que espalham a poeira lunar, evidenciando a operação bem diferente da acoplagem do ônibus espacial à estação. $O$ 
veículo lunar (figura 1D), que também executa um voo, tem uma configuração bastante diversa dos outros dois. Sua lógica é a da verticalidade/horizontalidade, como a de um veículo terrestre. Ali dentro há o efeito claro de peso, um peso de intensidade lunar, evidentemente, mas essa diferença não é explorada. De qualquer modo, há o peso. Manter a nave em voo exige que os motores estejam sempre em operação, e isso é evidenciado pelo ruído constante nas cenas internas. As tomadas externas têm como áudio apenas a trilha sonora com tom de suspense e nenhum ruído, no silêncio lunar provocado pela ausência de atmosfera. Não há qualquer indício de fumaças ou vapores. $\mathrm{O}$ funcionamento dos motores de reação em um ambiente lunar não provocaria tais efeitos visuais. $O$ diretor opta sempre pela precisão física em detrimento de uma narrativa que violasse as leis naturais, como ruídos no espaço e jatos fulgurantes, efeitos certamente mais impressionantes do que o silêncio. Dentro desse veículo, os alimentos são sanduíches: não há risco de as migalhas se espalharem flutuando nave afora. E há café em uma garrafa térmica. A física está nos mínimos detalhes.

\section{Uma análise semiótica}

A semiótica de Greimas (1973) e Greimas e Courtés (2008) fornece uma heurística para abordar o problema da significação. Ela fornece elementos que se interconectam em camadas de sentido, cada vez mais abstratas, a partir da consideração de um texto como uma narrativa em que um sujeito está em busca de um objeto de valor. O chamado percurso gerativo do sentido considera três níveis do texto. O primeiro deles, o nível discursivo (GREIMAS; COURTÉS, 2008, p. 143), ao mesmo tempo o mais superficial, visível e concreto, é aquele mais diretamente perceptível ao leitor. Nesse nível, são considerados os processos de construção dos atores, do espaço e do tempo da narrativa, em sua realização concreta. Além disso, são considerados as figuras e os temas, ou seja, o processo de figurativização trazido pelos elementos da narrativa; consideramos concretamente os personagens da história, os espaços e os tempos retratados, e procuramos estabelecer possíveis representações figurativas que tais elementos sugiram. No segundo nível, o narrativo (GREIMAS; COURTÉS, 2008, p. 330), não temos mais personagens, mas actantes, entendidos aqui como qualquer agente que realize uma ação. Em uma espécie de gramática do texto, consideramos o sujeito da narrativa como um actante que está em busca de um objeto. A narrativa se constitui em uma transformação de estado que considera relações de conjunção, em que o actante está de posse do valor pretendido, ou disjunção, em que o actante está alijado do objeto. A identificação do sujeito e de objeto bem como de outros actantes canônicos é parte fundamental da heurística da semiótica greimasiana. O terceiro nível, denominado fundamental ou profundo (GREIMAS; COURTÉS, 2008, p. 387), o mais abstrato de todos, considera valores abstratos presentes na narrativa e suas possíveis oposições semânticas definidas em termos de operações lógicas de asserção e negação.

As análises em cada um dos níveis produzem sentidos nos demais e permitem estabelecer as relações existentes no texto de forma sistemática. Descreveremos mais detalhadamente cada um desses níveis, ao mesmo tempo em que realizamos a análise do filme em questão. Nossa análise da segunda parte de 2001: uma odisseia no espaço se iniciará a partir do nível narrativo. 


\section{O nível narrativo}

No nível narrativo, temos um sujeito em busca de um objeto de valor abstrato. Esse sujeito, na segunda parte de 2001: uma odisseia, é o Dr. Heywood Floyd. A pergunta-chave para iniciar a compreensão da narrativa é em busca do que esse sujeito está. A história nos diz que Floyd foi até a Lua para avaliar a situação da descoberta do estranho objeto que foi desenterrado pela equipe de cientistas da base lunar norte-americana. A questão que é colocada é como essa descoberta poderá ser comunicada ao público em geral e, para isso, Floyd está incumbido de coletar a maior quantidade de informações possível. O objeto de valor que está sendo perseguido aqui pode ser descrito como o controle. Esse controle da situação, tomado em um plano mais geral, representa o controle do ser humano sobre a natureza e o controle político do conhecimento.

No nível narrativo consideramos quatro etapas razoavelmente bem definidas, assim denominadas: a manipulação, a competência, a performance e a sanção (PIETROFORTE, 2009, p. 14). A manipulação é a fase em que ocorre a constituição do sujeito e de sua busca. Na competência, o sujeito é dotado dos chamados objetos modais - saber e poder - necessários para a consecução do programa narrativo. A performance é a etapa onde o sujeito entra em conjunção (ou não) com seu objeto de valor. Finalmente, a sanção é o momento em que ocorrem as avaliações, os reconhecimentos e as revelações (Quadro 1).

Quadro 1. Fases do nível narrativo

\begin{tabular}{|c|c|c|c|}
\hline Manipulação & Competência & Performance & Sanção \\
\hline Constituição do sujeito & $\begin{array}{c}\text { Aquisição do saber } \\
\text { e do poder }\end{array}$ & Realização do programa & $\begin{array}{c}\text { Avaliaçãoe } \\
\text { reconhecimento }\end{array}$ \\
\hline
\end{tabular}

Fonte: elaborado pelo autor.

Há basicamente quatro modalidades de manipulação, denominadas: tentação, intimidação, sedução e provocação. A manipulação é uma ação realizada por um actante, denominado destinador da manipulação, em direção a outro actante, que se constituirá como sujeito. $\mathrm{Na}$ tentação, o manipulador oferece um prêmio como recompensa para a ação, enquanto, na intimidação, ele ameaça com um castigo. Dizemos que são manipulações baseadas no poder, na medida em que o manipulador é dotado da possibilidade de oferecer o prêmio ou o castigo. A sedução e a provocação, por sua vez, são baseadas em enunciados de saber sobre o sujeito, sendo que a sedução se constrói sobre elogios, e a provocação sobre desafios morais.

No nosso exemplo, o manipulador é o objeto desconhecido. Sua descoberta produz uma ameaça à segurança e ao controle. No âmbito geral da história de 2001: uma odisseia no espaço, a questão vai bem além disso, mas, nesse trecho, trata-se, fundamentalmente, dessa ameaça. É uma manipulação do tipo intimidação. A descoberta que provoca a manipulação, pressuposta, localiza-se antes da narrativa. O trecho se inicia, efetivamente, na fase da competência, com Floyd coletando informações (aquisição do saber) sobre a situação. A aquisição do 
poder está representada por todo o aparato tecnológico que permite a viagem à Lua e a descoberta e estudo do objeto. Mas, nesse caso, temos um exemplo no qual a performance não é concluída com a conjunção do sujeito com seu objeto de valor. O monólito provoca, no final da cena, um ruído ensurdecedor que afeta os astronautas. O controle não é atingido e o sujeito continua apartado de seu objeto de valor. A sanção ocorre como um valor negativo de nãorevelação, ao invés da revelação esperada. Imediatamente, corta-se para a outra parte do filme, onde uma nova narrativa de busca se inicia.

Nosso interesse, entretanto, está focado na questão da física envolvida nesse processo todo: as manobras das espaçonaves, sua configuração física, e todos aqueles elementos que normalmente são considerados como interessantes para uma discussão conceitual e didática. O que a análise do nível narrativo nos mostra é que tais elementos constituem a etapa da competência, mais precisamente, o objeto modal do poder. A segunda parte do filme se inicia após a célebre cena em que um hominídeo lança um fêmur ao ar. O corte leva a um artefato espacial em movimento, no minuto 19:50 do filme, quando se inicia a execução da valsa Danúbio Azul, de Strauss. A partir desse momento, são exibidos alguns artefatos espaciais em movimento, em sequência, orbitando a Terra. Todos os artefatos tecnológicos, é importante observar, foram modelados a partir de uma detalhada assessoria técnica, especializada em tecnologia aeroespacial e informática, de técnicos e empresas (BIZONY, 2000, p. 45).

A estação espacial girante aparece em seguida, em aproximação de câmera. Logo depois, surge o ônibus espacial, semelhante a um avião. No minuto 21:40, um corte leva ao interior desse veículo e mostra a cena em que uma comissária de bordo entra na cabine de passageiros, onde Floyd está dormindo, e pega uma caneta que flutua no ar, colocando-a de volta no bolso do cientista e desligando o televisor individual situado à frente do passageiro. Não há qualquer diálogo. Sem interrupção da valsa, as cenas de movimento continuam em 22:54, para mostrar a acoplagem do ônibus espacial à estação espacial, consumindo dois minutos e meio de exibição. Os pontos de vista das tomadas de câmera permitem colocar o espectador em diferentes referenciais durante esse procedimento. São três referenciais distintos. O primeiro deles situa-se a partir de tomadas externas, de diferentes ângulos, que permitem visualizar tanto o ônibus espacial quanto a estação girante. $\mathrm{O}$ segundo situa-se no ônibus espacial e dá a visão da janela da cabine de comando, em uma tomada que mostra o painel de controle e a ação dos pilotos da nave. Em um primeiro momento, eles visualizam a estação espacial, em movimento giratório, aproximando-se da nave. Um close é dado no painel de controle, onde se pode observar um logotipo da IBM, uma conhecida empresa de informática. O terceiro referencial está situado na estação espacial, fornecendo uma visão a partir do hangar de acoplagem, voltada para o exterior. A câmera se afasta para dentro da estação, lentamente, mostrando detalhes do hangar, as estrelas girando ao fundo e a aproximação do ônibus espacial. Entre os detalhes do hangar, há a sutil exibição de compartimentos onde há pessoas trabalhando, sendo que, na parte superior, as pessoas estão de cabeça para baixo em relação às do compartimento inferior, mostrando que o efeito centrífugo da rotação da estação produz a simulação da gravidade, mas com resultados um tanto incomuns.

Uma nova tomada externa mostra, agora, o ônibus espacial em movimento giratório, sincronizado ao da estação e aproximando-se dela. Passando novamente para o interior da cabine, vemos, agora, na janela da nave, a estação espacial sem movimento de rotação, apenas aproximando-se, enquanto o céu estrelado ao seu redor executa um movimento rotatório. $\mathrm{O}$ 
Piassi, L. P.

retorno à tomada externa mostra, finalmente, a acoplagem e a cena termina, juntamente com o final da execução da valsa, quando temos o corte para o interior da estação espacial, aos 25:25. A sequência completa ocupa, portanto, cinco minutos e meio do filme.

A sequência de acoplagem consome, portanto, um tempo considerável de exibição. Levando-se em conta que há outra sequência longa em que uma espaçonave sai da estação espacial e se dirige à Lua, também ao som de Strauss, podemos entender que há uma intenção explícita do diretor em mostrar cenas de manobra das espaçonaves e alguns fenômenos que ocorrem em seu interior, como a caneta flutuando, no caso mencionado; e alguns outros que ocorrem na segunda espaçonave, também associados à ausência de sensação de peso, como bandejas de alimento flutuando, toaletes de gravidade zero, e uma comissária de bordo que caminha pelas paredes e teto.

Em nosso método de análise, adotamos como pressuposto que, na obra cinematográfica, cada sequência está presente para desempenhar um papel na narrativa e que - ao menos em tese - é possível enquadrar esse papel em uma das etapas do nível narrativo. Adotando esse procedimento, podemos nos perguntar de que forma esse encaixe é realizado e que consequências advêm dessa relação. Considerando a sequência em questão, admitimos, como já exposto, que a segunda parte do filme expressa uma fase de competência. A manipulação, que instaurou o sujeito e o colocou em ação, está pressuposta em um momento anterior ao retratados nas cenas. Floyd já está se dirigindo à Lua, com a finalidade de realizar uma ação. Ação essa que, no final das contas, não se conclui, de forma que a fase da performance subentendese não realizada. Resulta, como já apontamos, que a etapa que estamos analisando corresponde à competência. Nesse sentido, cabe verificarmos de que forma temos aqui uma articulação com a aquisição do poder e do saber, que caracterizam essa etapa. E esse é um dos momentos em que percebemos que, ao contrário do que pode parecer em uma primeira análise, o sujeito da narrativa não é exatamente Floyd. Esse personagem é representante de uma classe maior, que poderia ser descrita, ainda que imprecisamente, como "a humanidade". De fato, as longas manobras, os detalhes das espaçonaves e dos fenômenos que ocorrem dentro e fora delas, associados de forma precisa àquilo que é previsto pelas leis físicas, pressupõem um arcabouço de conhecimento técnico e científico acumulado pelo gênero humano, que é o objeto modal do poder (a técnica) e do saber (a ciência) necessários para a consecução do programa narrativo. Kubrick e Clarke enfatizam isso e procuram transmitir, ao espectador, a mensagem de um futuro no qual podemos realizar coisas no espaço, graças ao desenvolvimento da ciência e da tecnologia. O ambiente espacial está sob controle, embora pequenos contratempos mostrem, por um lado, as dificuldades e, por outro, as possibilidades permanentes de aperfeiçoamento. De qualquer maneira, como pode-se verificar, é de um domínio confortável do espaço que o filme está nos falando, um domínio no qual um cientista pode dormir tranquilamente em uma aconchegante poltrona de uma espaçonave dotada de tudo o que se espera de um veículo de primeira classe turística. Isso representa um significativo objeto modal do poder. Não um poder no limite das possibilidades, mas um que se situa na zona do conforto.

\section{O nível discursivo}

O nível discursivo considera a constituição do espaço e do tempo da narrativa, bem como dos atores, agora tomados não como actantes abstratos, mas revestidos de suas caracte- 
rísticas, procurando estabelecer relações entre essas instâncias e o processo que leva das figuras aos temas (GREIMAS; COURTÉS, 2008, p. 44). Toda a sequência narrativa que mostra os veículos espaciais, suas performances e os fenômenos associados está realizando o processo de construir um espaço, um tempo e os atores.

Em relação ao processo de actorialização, podemos partir do personagem principal, Heywood Floyd, e passar a considerar sua aparência e comportamento. Floyd é um homem de idade em torno de 50 anos, que veste um terno formal, de cor marrom, e porta uma maleta de couro estilo 007. É um homem polido e simpático e denota liderança e inteligência. Está representando um órgão governamental ligado à ciência, o Conselho Nacional de Astronáutica, e tem a incumbência de coletar informações para elaborar um relatório sobre a situação que envolve a descoberta do objeto. Todos os demais personagens se caracterizam pelos trajes sóbrios e pelo comportamento polido e pela empatia. Mesmo o diálogo que Floyd tem com um grupo de cientistas russos, em que é explicitado um conflito, se dá de uma forma amigável, com diversas trocas de gentilezas e completa ausência de ironias ou agressividade de qualquer espécie. Outros personagens, como as equipes de serviços de bordo e receptividade, também se mostram de forma sóbria, cordial e empática, tanto em sua aparência como em seu comportamento.

Em relação à espacialização, há vários elementos a serem considerados. Destacaremos alguns deles. $\mathrm{O}$ interior da primeira espaçonave, por exemplo, retrata um veículo similar a um avião comercial, com a cabine dos pilotos isolada da dos passageiros, sendo que essa, com uma capacidade para um grande número de passageiros, assemelha-se a aeronaves de turismo. $\mathrm{O}$ interior da estação espacial tem uma estrutura similar a um hotel, com amplos espaços, área de recepção, poltronas dispostas em corredores. O logotipo de uma empresa aérea comercial (PanAm) aparece no exterior da nave, e o de uma rede hoteleira (Hilton) no interior da estação espacial.

Um dos principais elementos da constituição do tempo são os diversos artefatos tecnológicos que ajudam a construir uma noção de um futuro próximo com progresso e conforto: as espaçonaves e suas manobras precisas, os equipamentos computacionais que permitem a correta operação dos veículos e diversos itens, como os alimentos espaciais, o videofone, os televisores individuais nos encostos dos assentos, o sistema de identificação por voz, entre outros. Espaço, tempo e atores, portanto, constroem uma imagem de um futuro próspero, confortável, educado e civilizado, onde o controle da natureza se dá com sucesso, por meio do conhecimento científico e do desenvolvimento tecnológico. Todos os elementos contribuem para reforçar o sentido de um desenvolvimento da civilização, de que a humanidade atingiu um patamar no qual tem a natureza sob controle. Isso é mostrado em contraste com a primeira parte do filme, em que o ponto crucial era a própria sobrevivência da espécie e os conflitos entre concorrentes eram resolvidos a violentos golpes de fêmur, e não com cordiais convites para drinques.

Uma maneira de atentarmos para determinados aspectos que o cineasta pretende salientar é observar o uso da câmera. O close-up ou primeiro plano, que segundo Xavier (2008, p. 27) é caracterizado quando "a câmera, próxima da figura humana, apresenta apenas um rosto ou outro detalhe qualquer que ocupa a quase totalidade da tela", é empregado em alguns momentos. É isso que Kubrick faz com dois elementos na primeira sequência interna, onde a caneta de Floyd flutua na cabine de passageiros e uma comissária de bordo aparece para 
Piassi, L. P.

recolocá-la no lugar e desligar o monitor de TV individual do ilustre passageiro, que acabou por pegar no sono. O detalhe do calçado da comissária é fundamental, pois nele está escrito grip shoes, que nos informa que se trata de uma sapatilha aderente, empregada para atenuar o efeito da imponderabilidade no interior do veículo (Figura 2).

Figura 2. Calçados aderentes da aeromoça e a caneta de Floyd flutuando na cabine

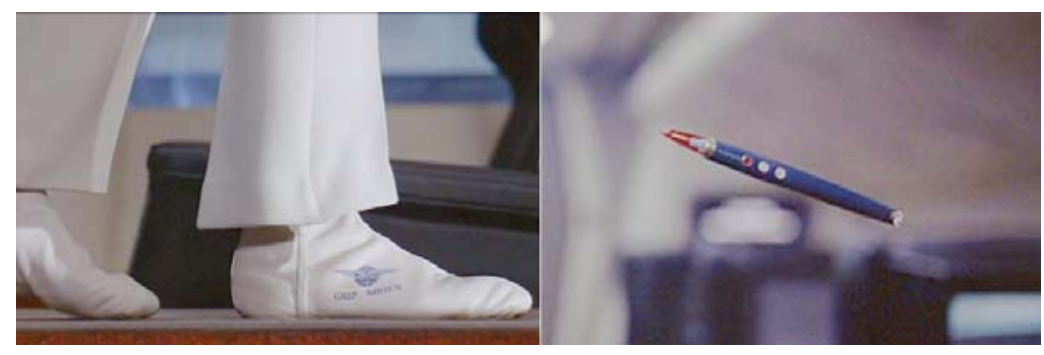

Fonte: 2001: uma odisseia no espaço (2001).

No entender de Telotte (2006), tais elementos configuram os dois aspectos que levantamos no item precedente: as dificuldades impostas pelo ambiente natural exótico do espaço, cujas leis físicas precisam ser levadas em conta, mas, também, as maneiras criativas que a humanidade encontra, por meio da ciência e da técnica, para, de alguma forma, superá-las, recriando assim, no meio espacial, a normalidade que encontramos no ambiente terrestre.

O ônibus espacial que leva Heywood Floyd até a estação, podemos observar repetidamente, coloca em primeiro plano o poder da gravidade, em parte ao sublinhar a sua ausência - por meio da caneta flutuante de Floyd, recuperada por uma aeromoça; seus braços, que ondulam enquanto ele dorme, como se ele estivesse flutuando na água, e o prolongado close-up dos sapatos especiais de gravidade da aeromoça, que lhe permitem operar normalmente, ainda que desajeitadamente, nas condições de gravidade zero do espaço. Tais detalhes, precisamente do tipo sobre os quais a maioria dos espectadores rapidamente observa, não apenas ilustram o estado de imponderabilidade verificado neste voo, mas também apontam o esforço humano em contrariar tal estado, a construção de gravidade onde esta não é natural. (TELOTTE, 2006, p. 46, tradução nossa)

Uma questão fundamental na análise da actorialização é verificar de que forma os atores são investidos semanticamente por meio de elementos que os caracterizam. E aqui temos dois atores. Um deles, Floyd, o outro, a comissária de bordo. O figurino e os objetos associados aos personagens são elementos fundamentais para a interpretação no processo de actorialização. 
Os calçados da comissária de bordo, por exemplo, além de serem calçados especiais para uso em ambientes de imponderabilidade, possuem determinadas características que nos permitem situá-los como calçados profissionais. Não há neles qualquer aspecto que sugira alguma conotação além do valor de uso. São sapatilhas de cano alto, muito flexíveis, aparentemente confeccionadas em couro macio totalmente branco, exceto pela aposição de um logotipo da empresa de aviação PanAm e dos dizeres grip shoes. Não há fechos ou aberturas de qualquer espécie, apenas uma tira lateral com fivela, que prende o sapato na barra da calça, cuja função parece ser a de evitar que, com a imponderabilidade, a extremidade inferior da calça se desloque para cima. A presença do logotipo reforça o sentido de um elemento de vestuário estritamente profissional. A sobriedade visual e a coloração sugerem, inclusive, uma conotação que se aproxima de um sentido higiênico, mais associado a ambientes hospitalares, embora mesmo calçados projetados para uso hospitalar possuam elementos estéticos que os situam além do mero valor de uso.

O mesmo não pode ser dito a respeito da caneta. Com um aspecto que lembra muito as tradicionais canetas-tinteiro, $\mathrm{o}$ artefato que flutua na cabine carrega consigo toda a conotação de sofisticação, luxo, formalidade, distinção e cultura associada a esses instrumentos de escrita. Não se trata, claro, de uma caneta-tinteiro convencional, pois possui alguns elementos a elas estranhos, como são os botões situados na superfície lateral. Tal caneta foi uma das várias encomendas que Kubrick fez a empresas diversas, para que projetassem o futuro de seus produtos.

Diz o release da Parken Pen Company na época (THE UNDERVIEW, 2008, tradução nossa):

Quando os espectadores saírem do cinema após assistir a fantástica aventura de Stanley Kubrick no futuro, provavelmente concordarão que as estrelas são as equipes de pesquisa das melhores empresas. Designers da Pen Parker, entre muitos outros, foram convidados por Kubrick para produzir modelos do que suas empresas podem ter no mercado daqui a 33 anos. Um exemplo de um produto do futuro é esta caneta atômica feita pela Pen Parker Company e empregada no filme. Incorporou-se um pequeno compartimento isotópico no interior da caneta para produzir energia que depois é convertida em calor. Isso faz variar o fluxo do reservatório de tinta da caneta a fim de que o escritor possa produzir uma ampla gama de espessuras de linha, desde o pouco visível até para um relevo marcado - característica exigida pela adição de uma terceira dimensão de escrita que os especialistas da Parker acreditam que pode se desenvolver durante as próximas três décadas. Mas nem adianta ir ao seu revendedor agora: a Parker não pretende colocar esta caneta à venda antes do próximo século.

A caneta é assim imaginada como um dispositivo de ejeção térmica de tinta, com o calor fornecido por isótopos radioativos cuja liberação é controlada pelo usuário. Assim como diversos outros elementos da história, um produto tecnológico imaginado para uma era espacial, em que a imponderabilidade era uma realidade. Mas, ainda assim, um produto luxuoso, 
que caracteriza distintamente quem a usa e, dessa forma, ajuda na construção da imagem de cientista veiculada no filme.

\section{O nível fundamental}

O nível fundamental ou profundo é aquele em que se estabelecem oposições entre categorias semânticas contrárias (PIETROFORTE, 2009, p. 11). Nossa análise permite estabelecermos algumas das dicotomias que estão implícitas no discurso do filme. Entre elas, poderíamos citar algumas como: progresso / atraso, civilização / barbárie, humano / animal, cultura / natureza. A oposição de valores semânticos contrários se dá por operações de asserção e negação. A passagem da condição de animal para humano, por exemplo, implica, primeiro, na negação da primeira condição para, depois, ocorrer a afirmação da segunda. Isso é representado por um diagrama denominado quadrado semiótico, representado na Figura 3.

Figura 3. Quadrado semiótico representando a oposição semântica humano-animal

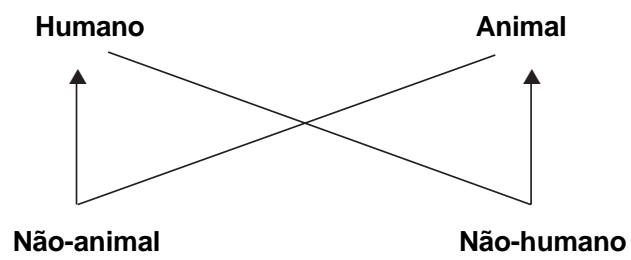

Fonte: elaborada pelo autor.

Na primeira parte do filme, a condição animal dos hominídeos é, inicialmente, afirmada na disputa de alimentos com outros animais e no perigo de ser predado por outros. Aos poucos, essa condição é negada, pelo uso do osso como instrumento e, finalmente, a condição humana é afirmada quando o fêmur, lançado para o alto, converte-se implicitamente na espaçonave. A segunda parte é justamente a reiteração dessa condição, não apenas de humano, mas de civilizado. É a afirmação do progresso, da transcendência para um plano superior da existência, figurativizada na ocupação civilizada do espaço, no conforto e no controle da situação. A segunda parte do filme reforça esse sentido.

A caneta de Floyd, para Gilbert (2006, p. 38), é outro elemento que, em contraste, remete ao osso. Assim como o satélite que aparece em substituição ao fêmur lançado para o alto, o formato cilíndrico da caneta reitera o do osso e simboliza o instrumento, a produção da cultura civilizada por meio da tecnologia. De um lado, o osso, primeiro passo arcaico do processo civilizatório, está associado a conteúdos de violência, rusticidade, brutalidade; ao passo que a caneta se opõe a esses sentidos, com conotações de racionalidade, sofisticação e 
delicadeza, aspectos que podem ser percebidos no comportamento dos educados e cordiais personagens de forma geral, inclusive quando em conflito. E justamente o conflito entre os russos e o americano Dr. Floyd, que relembra o embate entre os dois grupos de hominídeos, nos dá mais uma conotação que pode ser associada à caneta. Enquanto na disputa entre os ancestrais humanos a vantagem estava na posse de uma arma, um objeto físico de poder, no plano civilizado do ano 2001, a vantagem reside na posse da informação, que os norte-americanos detêm sobre a descoberta lunar, ao contrário de seus adversários.

A outra oposição, que podemos agora delimitar, é aquela existente entre a caneta e a sapatilha aderente. A caneta colorida e sofisticada distingue o cientista como pessoa importante, como aquele que detém o saber e, portanto, o poder. Está associada às mãos, que figurativizam o controle, e a um plano superior que remete ao progresso. Os sapatos, sóbrios e desprovidos de apelos estéticos, associam-se aos pés, e situam-se no plano inferior, no andar desajeitado da personagem que está ali para servir ao cientista e que, para fazê-lo, tem de se sujeitar ao descontrole provocado pela imponderabilidade, expondo a fragilidade humana frente à natureza.

\section{Conclusões: o filme no contexto da sala de aula}

Dada a lógica narrativa da segunda parte de 2001: uma odisseia no espaço, voltada para a afirmação da capacidade humana no domínio do espaço, em um futuro próximo e em uma perspectiva convincente, de afirmação das possibilidades derivadas do progresso científico e tecnológico, podemos entender sua preocupação em apresentar os fenômenos decorrentes da vida no espaço e a forma como podemos lidar com eles. Justamente por isso, há a ênfase em uma descrição precisa, de acordo não apenas com as leis físicas, mas, também, com as especulações mais sensatas, dadas por consultores de tecnologia, sobre como podemos lidar com os problemas decorrentes da ausência de sensação de peso, entre outras coisas. Isso justifica as cenas demoradas, ao som da valsa Danúbio Azul de Strauss, em que diversos fenômenos interessantes são destacados.

É quase um documentário didático, faltando apenas um narrador. Não é de se admirar que professores de física mais entusiasmados se vejam nesse papel. O filme 2001: uma odisseia no espaço, mais do que um simples recurso didático, deve ser visto como o marco de uma época em que a ciência desempenhou um papel fundamental. O contexto sócio-histórico da guerra fria e sua contraparte talvez mais emocionante, a corrida espacial, tudo isso faz parte da cultura científica de uma época. Mais do que de didática de conceitos científicos, estamos falando aqui da ciência como cultura inserida no contexto sociocultural de uma sociedade. Uma obra como o filme de Kubrick vai muito além do potencial de um recurso atraente. É uma referência cultural importante, uma narrativa sobre a ciência e os desejos humanos, expressos na ideologia de uma sociedade que sustenta sua base material no conhecimento científico.

Usar 2001: uma odisseia no espaço em sala de aula, portanto, não é apenas uma questão de método didático eficiente. $\mathrm{O}$ filme em si talvez nem seja realmente o mais atraente sob o ponto de vista da ludicidade, se a ideia é estimular os estudantes. Mas a fruição artística que ele proporciona vai bem além disso. É no seu conteúdo e no seu contexto, na sua linguagem, na sua proposta de inovação que residem suas maiores qualidades. É justamente o que diferencia 
um clássico de uma obra qualquer, voltada para o entretenimento. Que é possível realizar atividades didáticas com esse filme, fica muito claro pelos diversos exemplos aqui dados. Cada pequeno detalhe, cada artefato e, mesmo, as peças de vestuário levam em conta uma condição nova, da vida em órbita da Terra, das dificuldades que isso envolve e das possibilidades de superação. Apenas esse aspecto já poderia ser uma fonte de atividades e questões. Mas há outras possíveis abordagens, ainda no âmbito das possibilidades tecnológicas dadas pelas condições físicas. Por exemplo, o apelo à imaginação. Os estudantes conseguem imaginar os problemas colocados pelas condições de vida no espaço? Suas possíveis soluções?

Outra abordagem interessante é questionar os estudantes sobre como eles imaginam que seja hoje, verdadeiramente, a experiência espacial, os veículos, a estação espacial internacional, e quais diferenças eles esperam observar entre aquilo que é retratado no filme e a realidade. Mais do que isso, discutir as razões possíveis para as diferenças observadas, razões essas que vão desde aspectos sociais e históricos, referentes aos diferentes contextos políticos da década de 1960 e atual, até as estratégias ficcionais e sua ligação com certa ideologia de época, que enxerga, no espaço, mais uma fronteira para o universo do consumo. Também é possível lançar questões sobre o âmbito social da ciência. Como são caracterizados os cientistas no filme? Suas ações, comportamentos e discursos veiculam qual imagem de cientista e do papel da ciência? Em que medida tal imagem reflete uma certa visão de mundo a respeito da ciência?

O que talvez não seja imediatamente evidente, e que justifica nossa argumentação, é a articulação entre o discurso científico presente no filme e as necessidades narrativas, decorrentes de um debate ideológico de uma época crucial na história da ciência e da exploração espacial. Dessa forma, o que procuramos defender neste artigo, sustentados pela análise da obra, é que o uso didático de um filme dessa natureza (poderíamos citar alguns outros, igualmente interessantes) deve levar em conta seu valor cultural, suas possibilidades como expressão de uma época e como antecedente da época em que vivemos, em que o significado da exploração espacial e da ciência a ela subjacente adquiriu novos contornos, bem diferentes, mas compreensíveis a partir dos desdobramentos históricos desde então.

A análise semiótica nos permite observar tais aspectos nos menores detalhes e, com isso, volta nossa atenção para possíveis encaminhamentos de discussão em sala de aula. As relações entre a ciência e o público em geral, o papel do conhecimento científico e do desenvolvimento tecnológico e a noção de progresso, o próprio conceito de progresso em si, tudo isso está ali presente. O que significa o fato de que, com todo o conhecimento e desenvolvimento, o monólito negro descoberto continua um mistério que foge ao controle? A ciência como base para a concepção dos mais variados artigos e produtos implica que sentido de evolução? Quais os limites dessa evolução? Conseguir fazer com que os estudantes percebam tais questões presentes no discurso da obra é uma maneira de dar um significado abrangente aos conceitos científicos ali retratados.

Apresentar o filme em sala de aula apenas para elucidar conceitos físicos é, nesse sentido, aproveitar muito menos do que ele pode oferecer. Uma obra como essa permite emoldurar os conceitos e fenômenos em um rede maior de discussões sociais e filosóficas, e ser um ponto de apoio em uma prática educativa que se pretende reflexiva. No nosso entender, o filme traz questões extremamente relevantes para os dias de hoje. Talvez a mais interessante delas seja, por que, afinal, o ano de 2001 já é um passado com mais de uma década e ainda não temos bases lunares e imensas estações espaciais girantes? Teriam Kubrick e Clarke realmente errado 
previsões? Ou, de fato, era aquilo o que o contexto do momento sugeria? E por que, passados esses anos, o interesse pela exploração do espaço tornou-se tão menor? Se o filme não fornece as respostas, ao menos traz importantes perguntas. O futuro que se esperava não chegou. Podemos nos perguntar sobre o futuro de hoje. O que podemos esperar dele?

\section{Referências}

2001: uma odisseia no espaço. Direção: S. Kubrick. Intérpretes: Keir Dullea; Gary Lockwood. Vídeo. [S.l.]: Warner, 2001. 1 DVD (148 min), son., color.

BIZONY, P. Shipbuilding. In: SCHWAN, S (Org.). The making of 2001: a space odyssey. New York: Modern Library, 2000. p. 43-54.

BORGWALD, J. M. et al. Classroom analysis of rotating space vehicles in 2001: a space odyssey. The physics teacher, College Park, v. 31, n. 7, p. 406-409, 1993.

CALVINO, I. Porque ler os clássicos. 5. ed. São Paulo: Companhia das Letras, 1993.

CANDIDO, A. O direito à literatura. In: . Vários escritos. 3. ed. São Paulo: Duas

Cidades, 1995.

CORTÁZAR, J. Valise de cronópio. 2. ed. São Paulo: Perspectiva, 1993. (Série Debates, 104).

DUBECK, L. W. et al. Science fiction aids science teaching. Physics Teacher, College Park, v. 43, n. 7, p. 316-319, May 1990.

. Finding facts in science fiction films. The Science Teacher, Arlington, v. 60, n. 4, p. 46-48, Apr.1993.

FRAKNOI, A. Teaching astronomy with science fiction: a resource guide. Astronomy

Education Review, Tucson, v. 1, n. 2, p. 112-119, Jul. 2002 / Jan. 2003.

GEDULD, C. The production: a calendar. In: SCHWAN, S. (Org.). The making of 2001: a space odyssey. New York: Modern Library, 2000. p. 3-10.

GILBERT, J. Auteur with a capital A. In: KOLKER, R. Stanley Kubrick's 2001: a space odyssey: new essays. Oxford: Oxford University Press, 2006. p. 29-42

GREIMAS, A. J. Semântica estrutural. São Paulo: Cultrix: Edusp, 1973.

GREIMAS, A. J.; COURTÉS, J. Dicionário de semiótica. São Paulo: Contexto, 2008.

NEVES, M. C. D. et al. Science fiction in physics teaching: improvement of science education and history of science via informal strategies of teaching. Revista de Ciências Exatas e Naturais, Guarapuava, v. 1, n. 2, p. 91-101, 2000. 
Piassi, L. P.

PIASSI, L. P. C. Contatos: a ficça Po cientiìfica no ensino de ciências em um contexto sociocultural. 2007. 453 f. Tese (Doutorado) - Faculdade de Educação, Universidade de Sabo Paulo, SaPo Paulo, 2007.

PIETROFORTE, A. V. Análise textual da história em quadrinhos: uma abordagem semiótica da obra de Luiz Gê. São Paulo: Annablume: Fapesp, 2009.

PIETROCOLA, M. et al. Física em contextos: pessoal, social e histórico. São Paulo: FTD, 2011. v. 1.

SÃO PAULO. (Estado). Secretaria Estadual da Educação. Física: ciências da natureza e suas tecnologias. Caderno do Aluno. Ensino Médio. $1^{\text {a }}$ série. São Paulo: Secretaria Estadual da Educação, 2010. v. 4.

SIGNORELLI, V. I. O movimento relativo no filme "2001: uma odisséia no espaço". São Paulo: Fundação Telefônica, 2003. Disponível em: <http://is.gd/MfV9wP>. Acesso em: 09 jan. 2013.

SNYDERS, G. A alegria na escola. São Paulo: Manole, 1988.

Alunos felizes: reflexão sobre a alegria na escola a partir de textos literários. 2. ed. Rio de Janeiro: Paz e Terra. 1996.

STAR wars: episódio IV: a nova esperança. Direção: G. Lucas. Intérpretes: Mark Hammil; Harrison Ford. Vídeo. [S.l]: Fox, 2006. 1 DVD 121 min), son, color.

TELOTTE, J. P. The gravity of 2001: a space odyssey. In: KOLKER, R. Stanley Kubrick's 2001: a space odyssey: new essays. Oxford: Oxford University Press, 2006. p. 43-54.

THE UNDERVIEW on 2001: how was it done? [S.l.: s.n.], 2008. Disponível em: <http:// is.gd/8vcE1I >. Acesso em: 9 jan. 2013.

UNIVERSIDADE ESTADUAL DE CAMPINAS. Pró-Reitoria de Graduação. Comissão Permanente para os vestibulares. Física. In: . Unicamp 2001: caderno de questões: a Unicamp comenta suas provas. Campinas, Universidade Estadual de Campinas, 2001. p. 97-111. Disponível em: <http://www.comvest.unicamp.br/vest_anteriores/2001/ download/comentadas/Fisica.pdf>. Acesso: 9 ago. 2013.

XAVIER, I. O discurso cinematográfico. 4. ed. Rio de Janeiro: Paz e Terra, 2008.

Artigo recebido em 2701/13. Aceito em 07/05/13. 